\title{
Article
}

\section{The Impact of Diabetes Mellitus in Patients with Chronic Obstructive Pulmonary Disease (COPD) Hospitalization}

\author{
Kulothungan Gunasekaran ${ }^{1, *(\mathbb{D})}$, Swetha Murthi ${ }^{2}$, Kalaimani Elango ${ }^{3}\left(\mathbb{D}\right.$, Mandeep Singh Rahi ${ }^{1}$, \\ Bright Thilagar $\left.{ }^{4} \mathbb{(}\right)$, Sathishkumar Ramalingam ${ }^{5}$, Dinesh Voruganti ${ }^{6}$, Vijaya Kumar Paramasivam ${ }^{7}$, \\ Krishna Prasad Kolandaivel ${ }^{8}$, Ashish Arora ${ }^{9}$ and Arul Chandran ${ }^{10}{ }^{6}$
}

Citation: Gunasekaran, K.; Murthi, S.; Elango, K.; Rahi, M.S.; Thilagar, B.; Ramalingam, S.; Voruganti, D.; Paramasivam, V.K.; Kolandaivel, K.P.; Arora, A.; et al. The Impact of Diabetes Mellitus in Patients with Chronic Obstructive Pulmonary Disease (COPD) Hospitalization. J. Clin. Med. 2021, 10, 235. https://doi.org/10.3390/ jcm10020235

Received: 24 December 2020 Accepted: 8 January 2021 Published: 11 January 2021

Publisher's Note: MDPI stays neutral with regard to jurisdictional clai$\mathrm{ms}$ in published maps and institutional affiliations.

Copyright: (C) 2021 by the authors. Licensee MDPI, Basel, Switzerland. This article is an open access article distributed under the terms and conditions of the Creative Commons Attribution (CC BY) license (https:// creativecommons.org/licenses/by/ $4.0 /)$.
1 Division of Pulmonary Diseases and Critical Care, Yale-New Haven Health Bridgeport Hospital, 267 Grant Street, Bridgeport, CT 06610, USA; sunny.mandeep@gmail.com

2 Division of Endocrinology and Metabolism, Lenox Hill Hospital, 110 e 59th Street, New York, NY 10022, USA; drswethamurthi@gmail.com

3 Department of Cardiology, University of Nevada Las Vegas, 1701 W Charleston Blvd, Las Vegas, NV 89102, USA; kalaimani.elango@gmail.com

4 Division of Hospital Medicine, Henry Ford Hospital, 2799 W Grand Blvd, Detroit, MI 48202, USA; bright.pearson@gmail.com

5 Division of Hospital Medicine, Lovelace Medical Center, 601 Dr. Martin Luther King Jr. Ave NE, Albuquerque, NM 87102, USA; sathishmed@gmail.com

6 Division of Cardiology, University of Arkansan Medical Sciences, 4301 W Markham Street, Little Rock, AR 72205, USA; dineshvoru@gmail.com

7 Division of Nephrology, Bay State Medical Center, S 759 Chestnut Street, Springfield, MA 01199, USA; ronvijay@yahoo.com

8 Division of Oncology, St. Joseph Medical Center, 523 N 3rd Street, Brainerd, MN 56401, USA; prasadarsenal87@gmail.com

9 Division of Pulmonary Diseases and Critical Care, Saint Mary's Hospital, 56 Franklin Street, Waterbury, CT 06610, USA; docashely@yahoo.co.uk

10 Division of Pulmonary Diseases and Critical Care, Hurley Medical Center, G-3252 Beecher Road, Flint, MI 48532, USA; arulchandranmd@gmail.com

* Correspondence: stankuloth@gmail.com

Abstract: (1) Background: Chronic obstructive pulmonary disease (COPD) is the leading cause of morbidity and mortality worldwide. Diabetes mellitus (DM) has been shown to have adverse inflammatory effects on lung anatomy and physiology. We investigated the impact of DM on COPD patient outcomes during inpatient hospitalization. (2) Methods: We conducted a retrospective analysis using the Nationwide Inpatient Sample (NIS) over the years 2002-2014. Three groups, COPD without diabetes, COPD with diabetes but no complication, and COPD with DM and complication, were analyzed. (3) Results: A total of 7,498,577 were COPD hospitalization; of those, 1,799,637 had DM without complications, and 483,467 had DM with complications. After adjusting for clinical, demographic, and comorbidities, the odds of increased LOS in the COPD/DM with complication were 1.37 (confidence interval (CI): 1.326-1.368), and those of DM without complication were 1.061 (1.052-1.070) when compared with COPD alone. The odds of pneumonia, respiratory failure, stroke, and acute kidney injury were also higher in COPD hospitalizations with DM. Both DM with complication (odds ratio (OR): 0.751 (CI 0.727-0.777)) and DM without complication (OR: 0.635 (CI: 0.596-0.675)) have lesser odds of mortality during hospitalization than with COPD alone. (4) Conclusions: There is a considerable inpatient burden among COPD patients with DM in the United States.

Keywords: COPD; chronic obstructive pulmonary disease; diabetes mellitus; length of stay; pneumonia; respiratory failure; stoke; kidney injury 


\section{Introduction}

Chronic obstructive pulmonary disease (COPD) is a chronic inflammatory lung disease that causes progressive airflow obstruction, which is not fully reversible. The airflow limitation is associated with an abnormal inflammatory response of the lung to noxious particles or gases. According to the Global Initiative for Chronic Obstructive Lung Disease (GOLD) 2020 report, COPD is the leading form of lung disease causing morbidity and mortality worldwide. It is associated with a substantially increasing economic and social burden [1,2]. According to a systematic review and meta-analysis published by Adiloye et al. in 2015, there were about 384 million COPD cases in 2010, with an estimated global prevalence of around 11.7\% [3]. Globally, there were about 3 million deaths due to COPD annually [4]. With the increase in the prevalence of smoking and aging in the patient population, the prevalence of COPD is projected to rise over the next 40 years. There may be more than 5.4 million annual deaths from COPD and related conditions in 2060 [5].

Studies have shown that morbidities in COPD increase with age [6] and are also affected by other comorbid conditions like diabetes and cardiovascular diseases [7]. These chronic conditions impair the patient's health status and affect COPD management, adding to the economic and social burden.

Diabetes is one of the leading causes of morbidity and mortality in the world. It was the seventh leading cause of death in the United States in 2017. According to the Centers for Disease Control and Prevention (CDC) 2020 report, about 34.2 million people have diabetes, which is about $10.5 \%$ of the U.S. population, and 88 million people aged 18 years and older have prediabetes (about $34.5 \%$ of U.S. adult population) [8]. About 1.5 million Americans are diagnosed with diabetes every year.

Diabetes is a metabolic disorder characterized by hyperglycemia, resulting from insulin production defects, action, or both. Chronic hyperglycemia is associated with dysfunction and long-term damage to various organs such as the kidneys, eyes, heart, and blood vessels. Studies have shown that there is an association of inflammation with diabetes where there is an increase in the circulating levels of inflammatory markers, including $C$ reactive protein (CRP), interleukin-6 (IL-6), and fibrinogen, which lead to insulin resistance [9]. This chronic systemic inflammation forms the most common denominator for COPD and DM. Several studies have shown that diabetes has a significant implication on the respiratory condition, including COPD, obstructive sleep apnea, and interstitial lung disease [10-12]. Diabetes mellitus (DM) in COPD patients was found to affect their lung function and, in turn, their prognosis [13,14], but their impact on COPD hospitalizations in terms of pneumonia, acute respiratory failure, stroke, acute kidney injury, and inhospital mortality has not been studied. COPD patients with comorbid DM are shown to have an increase in their length of stay [14]. Identifying the factors that affect the length of stay and charges incurred during the hospital stay can help provide better insight to the physicians regarding managing these chronic conditions. Given the association between COPD and $\mathrm{DM}$, we investigated DM's impact on COPD outcomes during inpatient hospitalization.

\section{Materials and Methods}

\subsection{Data Source}

The data that support the findings of this study are available from the corresponding author on reasonable request. The study examined the impact of diabetes mellitus (DM) on COPD hospitalizations using discharge data from the National Inpatient Sample (NIS), Healthcare Cost and Utilization Project (HCUP), and Agency for Healthcare Research and Quality [15]. The NIS is the largest publicly available all-payer inpatient care database in the United States (US), containing data on more than seven million hospital stays per year. NIS is a self-weighted, stratified, systematic, random sample of $20 \%$ discharges from all nonfederal U.S. community hospitals (before 2012, it was a 20\% sample of hospitals from which all discharges were retained). To account for this redesign, the trend weight (TRENDWT) provided by HCUP is used in place of the original discharge weight (DISCWT) to create national estimates for years before 2012 [16]. The NIS sample is stratified on hospital 
characteristics. This clustering form tends to induce dependence among discharges within hospitals; hence, variance analysis of subsets in line with NIS methods [17] was performed. Because this study included de-identified data, per the data use agreement with the Agency for Healthcare Research and Quality, ethical clearance and patient consent were not sought.

\subsection{Study Population and Variables}

We used International Classification of Diseases, Ninth Revision, Clinical Modification (ICD-9-CM) codes to identify all hospitalized adults (aged $\geq 18$ years) who had a primary diagnosis of COPD (ICD-9-CM diagnosis codes 491.2, 491.20, 491.21, 491.22, 492, 492.0, 492.8, 496) between January 2002 and December 2014. Those with missing data for gender, mortality, and length of stay were excluded. Those coded for "DISPUNIFORM = Transfer to Short-term Hospital" and "Admission source, uniform coding-ASOURCE = transfer from another hospital" for the years 2002-2007 and "Indicator of a transfer into the hospital-TRAN_IN = Transferred in from a different acute care hospital" for the years 2008-2014 were also excluded to avoid duplication of discharges, which yielded a final sample size of 7,498,577. Dummy cases with hospital identifiers were added to ensure all the hospitals in the United States, irrespective of COPD diagnosis, were added to the analysis to account for the NIS database's intricate sampling design considering the clustering effect.

Among COPD admissions, those with DM were extracted using the clinical classification of diseases software (CCS) code [18] from the secondary diagnoses numbers DXCCS2-DXCCS30. CCS code 49 is used for DM without complication, CCS code 50 is used for DM with complications, and those without any of the above codes were named "COPD with no DM". DM with complications includes patients with DM and complications like ketoacidosis, hyperosmolarity, coma, renal, ophthalmic, neurological, or peripheral vascular disease manifestation. NIS provides 29 comorbidities (also known as Elixhauser comorbidity measures) based on ICD-9 CM diagnoses and the diagnosis-related group in effect on the date of discharge. These comorbidities are not directly related to the principal diagnosis or the main reason for admission and are likely to have originated before the hospital stay [19]. Additional comorbidities and clinical outcomes were extracted using ICD-9-CM diagnosis and procedure codes described in the Supplementary Table S1.

\subsection{Outcomes}

Our study aimed at finding the differences in outcomes such as hospital length of stay, the incidence of pneumonia, respiratory failure, acute kidney injury, and stroke among three subgroups of COPD inlcuding COPD with no DM, COPD with DM without complication, and COPD with DM with complication.

\subsection{Statistical Analyses}

We adhered to the methodological standards described by Khera et al. [20]. All data analyses were performed using IBM SPSS Statistics for Windows, version 24.0 (IBM, Armonk, New York, NY, USA). The study analysis was done using a complex sample analysis method accounting for the sample design's clustering effect. Weight is applied to obtain national estimates. Continuous values are reported as mean \pm standard error of the mean and compared using analysis of variance (ANOVA). Categorical variables were reported as a number and/or percentage and compared using the Chi-square test. Multivariable logistic regression analyses were done while accounting for the sampling technique and adjusting for various demographic variables, including age, clinical variables, and hospital characteristics.

\section{Results}

Out of 7,498,577 (sample size N) patients with COPD over 18 years, 521,5474 (69.55\%) did not have diabetes. Of those remaining patients who had diabetes $(n=2,283,103)$, about $21.18 \%$ of patients $(n=483,467)$ had complications due to diabetes. There was more female representation in the sample population; about $55.8 \%$ of those with COPD without DM were females. The mean age of all COPD patients was 68.92 years (interquartile range (IQR) 
$68.86,68.98$ years). Of those patients without $\mathrm{DM}$, the mean age was about $69.17 \pm 0.035$. Compared with those without DM complications, patients with DM complications were younger (68.57 \pm 0.036 vs. $67.55 \pm 0.051$ ). Among all COPD admissions, about $66.8 \%$ were Caucasians, followed by African-Americans (8.1\%). The ethnic distribution was similar among those patients with no DM (67.7\% and 7.2\% respectively), DM with no complications (65.2\% and 9.8\% respectively), and DM with complications $(63.1 \%$ and $11.5 \%$ respectively). About $30.3 \%$ of COPD patients without DM were current smokers compared with $26 \%$ and $24 \%$ in diabetic patients without complications and with complications, respectively $(p<0.001)$ (Table 1$)$.

Table 1. Demographic characteristics of chronic obstructive pulmonary disease (COPD) hospitalizations with and without diabetes mellitus (DM).

\begin{tabular}{|c|c|c|c|c|c|}
\hline Clinical Characteristics & $\begin{array}{c}\text { All COPD } \\
(n=7,498,577)\end{array}$ & $\begin{array}{c}\text { COPD with No } \\
\text { DM }(n=5,215,474)\end{array}$ & $\begin{array}{c}\text { COPD with DM } \\
\text { without Complication } \\
(n=1,799,636)\end{array}$ & $\begin{array}{c}\text { COPD with DM } \\
\text { with Complication } \\
(n=483,467)\end{array}$ & $p$-Value * \\
\hline Age (years) & $68.92 \pm 0.03$ & $69.17 \pm 0.03$ & $68.57 \pm 0.03$ & $67.55 \pm 0.05$ & $<0.0001$ \\
\hline \multicolumn{6}{|l|}{ Sex } \\
\hline Male $^{+}$ & $44.1 \%$ & $69.8 \%$ & $23.9 \%$ & $6.3 \%$ & \multirow{2}{*}{$<0.0001$} \\
\hline Female $^{\dagger}$ & $55.9 \%$ & $69.4 \%$ & $24.1 \%$ & $6.5 \%$ & \\
\hline \multicolumn{6}{|l|}{ Race (uniform) } \\
\hline White & $66.8 \%$ & $67.7 \%$ & $65.2 \%$ & $63.1 \%$ & \multirow{7}{*}{$<0.0001$} \\
\hline Black & $8.1 \%$ & $7.2 \%$ & $9.8 \%$ & $11.5 \%$ & \\
\hline Hispanic & $3.9 \%$ & $3.3 \%$ & $4.7 \%$ & $6.4 \%$ & \\
\hline Asian or Pacific Islander & $0.8 \%$ & $0.8 \%$ & $0.9 \%$ & $0.9 \%$ & \\
\hline Native American & $0.4 \%$ & $0.4 \%$ & $0.5 \%$ & $0.5 \%$ & \\
\hline Others & $1.4 \%$ & $1.3 \%$ & $1.5 \%$ & $1.7 \%$ & \\
\hline Missing & $18.6 \%$ & $19.3 \%$ & $17.4 \%$ & $16.0 \%$ & \\
\hline Current smoking & $28.8 \%$ & $30.3 \%$ & $26.0 \%$ & $24.0 \%$ & $<0.0001$ \\
\hline Past smoking & $20.0 \%$ & $19.8 \%$ & $20.6 \%$ & $19.5 \%$ & $<0.0001$ \\
\hline Admission day is a weekend & $23.9 \%$ & $23.8 \%$ & $24.1 \%$ & $23.9 \%$ & $<0.0001$ \\
\hline \multicolumn{6}{|l|}{ Disposition of patient (uniform) } \\
\hline Home or self-care & $67.3 \%$ & $68.0 \%$ & $66.5 \%$ & $63.0 \%$ & \multirow{6}{*}{$<0.0001$} \\
\hline Skilled nursing facility (SNF) & $14.3 \%$ & $14.2 \%$ & $14.4 \%$ & $15.1 \%$ & \\
\hline Home health care (HHC) & $15.3 \%$ & $14.5 \%$ & $16.6 \%$ & $19.6 \%$ & \\
\hline Against medical advice (AMA) & $1.3 \%$ & $1.3 \%$ & $1.2 \%$ & $1.2 \%$ & \\
\hline Died in hospital & $1.7 \%$ & $1.9 \%$ & $1.3 \%$ & $1.2 \%$ & \\
\hline Unknown & $0 \%$ & $0.1 \%$ & $0 \%$ & $0 \%$ & \\
\hline \multicolumn{6}{|l|}{$\begin{array}{l}\text { Elective versus non-elective } \\
\text { admission }\end{array}$} \\
\hline Non elective & $91.9 \%$ & $91.7 \%$ & $92.2 \%$ & $92.8 \%$ & \multirow{2}{*}{$<0.0001$} \\
\hline Elective & $8.1 \%$ & $8.3 \%$ & $7.8 \%$ & $7.2 \%$ & \\
\hline Number of comorbidities & $9.23 \pm 0.02$ & $8.46 \pm 0.02$ & $10.63 \pm 0.02$ & $12.40 \pm 0.04$ & $<0.0001$ \\
\hline \multicolumn{6}{|l|}{ Comorbid conditions } \\
\hline $\begin{array}{l}\text { Acquired immune deficiency } \\
\text { syndrome }\end{array}$ & $0.2 \%$ & $0.3 \%$ & $0.1 \%$ & $0.1 \%$ & $<0.0001$ \\
\hline Alcohol abuse & $3.8 \%$ & $4.4 \%$ & $2.5 \%$ & $2.1 \%$ & $<0.0001$ \\
\hline Deficiency anemias & $13.7 \%$ & $12.5 \%$ & $15.6 \%$ & $19.8 \%$ & $<0.0001$ \\
\hline $\begin{array}{c}\text { Rheumatoid arthritis/collagen } \\
\text { vascular diseases }\end{array}$ & $2.7 \%$ & $2.7 \%$ & $2.6 \%$ & $2.4 \%$ & $<0.0001$ \\
\hline
\end{tabular}


Table 1. Cont.

\begin{tabular}{|c|c|c|c|c|c|}
\hline Clinical Characteristics & $\begin{array}{c}\text { All COPD } \\
(n=7,498,577)\end{array}$ & $\begin{array}{c}\text { COPD with No } \\
\text { DM }(n=5,215,474)\end{array}$ & $\begin{array}{c}\text { COPD with DM } \\
\text { without Complication } \\
(n=1,799,636)\end{array}$ & $\begin{array}{l}\text { COPD with DM } \\
\text { with Complication } \\
(n=483,467)\end{array}$ & $p$-Value * \\
\hline Chronic blood loss anemia & $0.5 \%$ & $0.5 \%$ & $0.5 \%$ & $0.6 \%$ & $<0.0001$ \\
\hline Congestive heart failure & $25.0 \%$ & $21.3 \%$ & $31.8 \%$ & $40.0 \%$ & $<0.0001$ \\
\hline Coagulopathy & $2.2 \%$ & $2.1 \%$ & $2.3 \%$ & $2.9 \%$ & $<0.0001$ \\
\hline Depression & $14.3 \%$ & $14.1 \%$ & $14.9 \%$ & $15.4 \%$ & $<0.0001$ \\
\hline Drug abuse & $2.3 \%$ & $2.5 \%$ & $1.9 \%$ & $2.1 \%$ & $<0.0001$ \\
\hline Hypertension & $58.5 \%$ & $53.6 \%$ & $69.0 \%$ & $72.6 \%$ & $<0.0001$ \\
\hline Hypothyroidism & $11.4 \%$ & $10.9 \%$ & $12.5 \%$ & $13.5 \%$ & $<0.0001$ \\
\hline Liver disease & $1.7 \%$ & $1.6 \%$ & $1.8 \%$ & $2.4 \%$ & $<0.0001$ \\
\hline Lymphoma & $0.5 \%$ & $0.6 \%$ & $0.4 \%$ & $0.4 \%$ & $<0.0001$ \\
\hline Fluid and electrolyte disorders & $22.1 \%$ & $21.7 \%$ & $21.8 \%$ & $27.9 \%$ & $<0.0001$ \\
\hline Metastatic cancer & $1.2 \%$ & $1.4 \%$ & $0.9 \%$ & $0.8 \%$ & $<0.0001$ \\
\hline Other neurological disorders & $6.9 \%$ & $7.0 \%$ & $6.7 \%$ & $7.0 \%$ & $<0.0001$ \\
\hline Obesity & $11.0 \%$ & $6.6 \%$ & $19.0 \%$ & $28.2 \%$ & $<0.0001$ \\
\hline Paralysis & $1.1 \%$ & $1.0 \%$ & $1.1 \%$ & $1.3 \%$ & $<0.0001$ \\
\hline Peripheral vascular disorders & $7.3 \%$ & $6.8 \%$ & $7.6 \%$ & $11.1 \%$ & $<0.0001$ \\
\hline Psychoses & $5.1 \%$ & $4.8 \%$ & $5.5 \%$ & $5.8 \%$ & $<0.0001$ \\
\hline Pulmonary circulation disorders & $0.4 \%$ & $0.4 \%$ & $0.5 \%$ & $0.6 \%$ & $<0.0001$ \\
\hline Renal failure & $8.7 \%$ & $6.5 \%$ & $11.2 \%$ & $23.0 \%$ & $<0.0001$ \\
\hline Hemodialysis & $0.9 \%$ & $0.7 \%$ & $0.9 \%$ & $2.8 \%$ & $<0.0001$ \\
\hline Solid tumor without metastasis & $3.3 \%$ & $3.5 \%$ & $2.7 \%$ & $2.2 \%$ & $<0.0001$ \\
\hline $\begin{array}{l}\text { Peptic ulcer disease excluding } \\
\text { bleeding }\end{array}$ & $0.2 \%$ & $0.2 \%$ & $0.1 \%$ & $0.1 \%$ & $<0.0001$ \\
\hline Valvular disease & $5.6 \%$ & $5.5 \%$ & $5.6 \%$ & $6.1 \%$ & $<0.0001$ \\
\hline Weight loss & $3.2 \%$ & $3.7 \%$ & $2.0 \%$ & $2.1 \%$ & $<0.0001$ \\
\hline Atrial fibrillation and flutter & $14.4 \%$ & $13.7 \%$ & $16.0 \%$ & $16.7 \%$ & $<0.0001$ \\
\hline Coronary artery disease & $30.2 \%$ & $27.0 \%$ & $36.6 \%$ & $41.1 \%$ & $<0.0001$ \\
\hline Smoking & $42.5 \%$ & $44.2 \%$ & $39.1 \%$ & $36.6 \%$ & $<0.0001$ \\
\hline Hyperlipidemia & $27.4 \%$ & $23.2 \%$ & $36.3 \%$ & $40.8 \%$ & $<0.0001$ \\
\hline Obstructive sleep apnea & $8.5 \%$ & $5.4 \%$ & $14.3 \%$ & $19.5 \%$ & $<0.0001$ \\
\hline Marijuana & $0.3 \%$ & $0.3 \%$ & $0.2 \%$ & $0.2 \%$ & $<0.0001$ \\
\hline \multicolumn{6}{|l|}{ Outcomes } \\
\hline Died during hospitalization & $1.7 \%$ & $1.9 \%$ & $1.3 \%$ & $1.2 \%$ & $<0.0001$ \\
\hline Pneumonia & $14.0 \%$ & $13.8 \%$ & $14.5 \%$ & $14.4 \%$ & $<0.0001$ \\
\hline Respiratory failure & $9.2 \%$ & $8.7 \%$ & $10.0 \%$ & $11.4 \%$ & $<0.0001$ \\
\hline Stroke & $1.0 \%$ & $0.9 \%$ & $1.0 \%$ & $1.2 \%$ & $<0.0001$ \\
\hline Sepsis & $1.0 \%$ & $1.0 \%$ & $0.9 \%$ & $1.4 \%$ & $<0.0001$ \\
\hline ET intubation/mechanical ventilation & $2.3 \%$ & $2.3 \%$ & $2.2 \%$ & $2.5 \%$ & $<0.0001$ \\
\hline Acute kidney injury & $4.5 \%$ & $3.7 \%$ & $5.3 \%$ & $11.0 \%$ & $<0.0001$ \\
\hline \multicolumn{6}{|l|}{ Resource utilization } \\
\hline Length of stay (LOS in days) & $4.58 \pm 0.009$ & $4.52 \pm 0.01$ & $4.56 \pm 0.01$ & $5.22 \pm 0.02$ & $<0.0001$ \\
\hline LOS $\geq 4$ days & $52.2 \%$ & $51.0 \%$ & $53.4 \%$ & $60.8 \%$ & $<0.0001$ \\
\hline Total charges & $22,131.10 \pm 141.89$ & $21,321 \pm 141.93$ & $23,080 \pm 154.64$ & $27,328 \pm 234.90$ & $<0.0001$ \\
\hline
\end{tabular}

Categorical variables are displayed as mean \pm standard error of the mean. Continuous variables are expressed as $\%{ }^{*}=$ all $p$-values denote the comparison of each variable across three subgroups of COPD. Continuous variables across three subgroups are compared by analysis of variance (ANOVA), and categorical variables are compared by Pearson Chi-square test. ${ }^{\dagger}=$ percentages are derived by taking either male or female as a whole group for the three subgroups. 
Among all COPD patients who had approximately nine comorbid medical conditions, patients with DM and no complications had about ten chronic medical conditions. Those with DM complications had about 12 comorbidities. The typical chronic medical conditions included hypertension, congestive heart failure, obesity, fluid and electrolyte abnormalities/renal failure, deficiency anemias, depression, and hypothyroidism.

About $72.6 \%$ of the diabetic complications had hypertension compared with $53.6 \%$ in patients without diabetes. Congestive heart failure was also more common among diabetic patients with complications than those without diabetes $(40 \%$ and $21.3 \%$ respectively, $p$-value $<0.0001)$. Similarly, obesity was also more common in diabetic patients with complications than those without diabetic complications and those without diabetes ( $28.2 \%$ vs. $19 \%$ vs. $6.6 \%$, respectively).

Of diabetic patients with complications, about $23 \%$ had renal failure, and $27.9 \%$ had fluid and electrolyte abnormalities. In comparison, in the non-diabetic patient group, $6.5 \%$ had renal failure and $21.7 \%$ had fluid and electrolyte abnormalities.

About $15.4 \%$ of diabetic patients with complications were diagnosed with depression, compared with $14.1 \%$ in patients without diabetes. It was a statistically significant $(<0.0001)$ difference between the two groups, even though the absolute difference was small.

\subsection{Prevalence}

Our study results showed that diabetes mellitus was increasingly prevalent in patients with COPD hospitalizations for over ten years (Table 2) (Figure 1).

\subsection{Length of Stay}

When the length of stay (with $\geq 4$ days of hospital stay) was compared among the group, about $51 \%$ of patients without diabetes had a longer length of stay. As expected, about $60.8 \%$ of diabetic patients with complications had a longer length of stay compared with $53.4 \%$ of diabetic patients without complications $(p<0.001)$. After adjusting for clinical, demographic characteristics, and comorbidities, logistic regression analysis showed that patients with DM, but no complications had an odds of 1.061 (95\% confidence interval (CI) 1.052, 1.070) risk of having an extended hospital stay $\geq 4$ days. Diabetic patients with complications had an increased odds of 1.347 (95\% CI 1.326, 1.368) of having an extended hospital stay $\geq 4$ days compared with patients without DM. This was evident in the total charges incurred during the hospital stay among the patient population. Those patients without diabetes had a total cost of about $\$ 21,321.90$ (95\% CI 21,043.69, 21,600.11). This was much lower than the total charges incurred for the diabetic patients without complications and those with complications ( $\$ 23,080.01 \pm$ SE 154.647 vs. $\$ 27,328.29 \pm$ SE $234.908, p$-value $<0.0001)$.

Table 2. Trends of hospitalization for chronic obstructive pulmonary disease and diabetes mellitus in COPD 2005-2014.

\begin{tabular}{cccc}
\hline Calendar Year & $\begin{array}{c}\text { Total Number of COPD } \\
\text { Admissions }\end{array}$ & $\begin{array}{c}\text { Total Number of Admissions for } \\
\text { COPD with DM }\end{array}$ & $\begin{array}{c}\text { Inpatient Prevalence of DM (per 1,000,000 } \\
\text { Admissions) among COPD Patients }\end{array}$ \\
\hline 2002 & 548,528 & 116,211 & 211,860 \\
2003 & 551,403 & 126,200 & 228,872 \\
2004 & 492,379 & 115,465 & 234,503 \\
2005 & 554,147 & 137,344 & 247,849 \\
2006 & 524,685 & 140,828 & 268,405 \\
2007 & 521,399 & 156,782 & 300,695 \\
2008 & 628,521 & 195,251 & 310,652 \\
2009 & 642,172 & 221,822 & 345,424 \\
2010 & 621,362 & 218,531 & 351,697 \\
2011 & 644,382 & 229,464 & 356,100 \\
2012 & 622,720 & 221,365 & 355,481 \\
2013 & 598,379 & 210,595 & 351,942 \\
2014 & 548,500 & 193,245 & 352,315 \\
Total & $7,498,577$ & $2,283,104$ & 304,472 \\
\hline
\end{tabular}




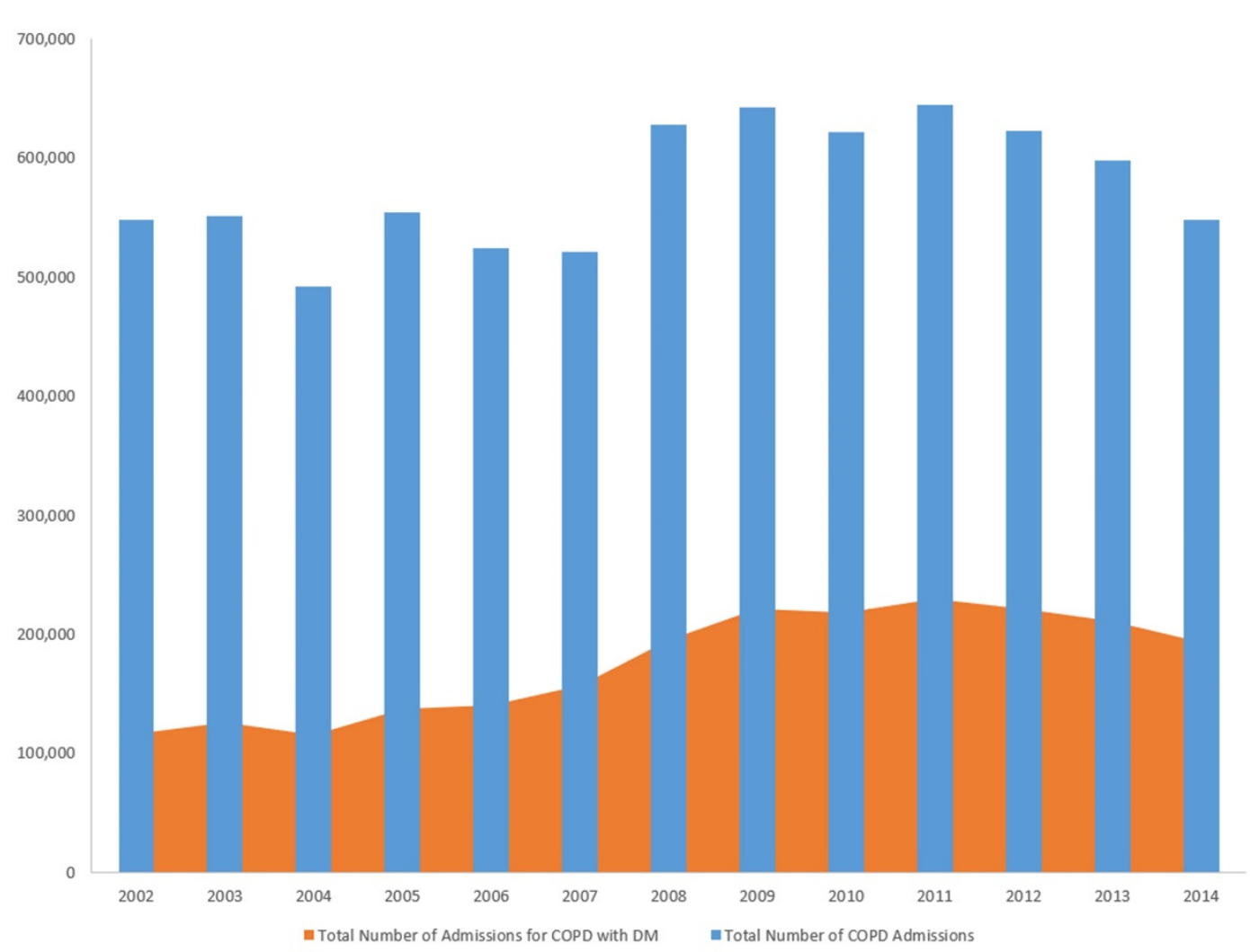

Figure 1. Trends of hospitalization for chronic obstructive pulmonary disease (COPD) and diabetes mellitus (DM) in COPD 2005-2014.

\subsection{Outcomes}

Logistic regression was performed to assess the odds of developing pneumonia, respiratory failure, acute kidney injury, stroke, and mortality after adjusting for clinical, demographic characteristics, and comorbidities (Table 3). The odds of pneumonia were statistically significant between diabetic patients with complications (odds ratio (OR) 1.04, 95\% CI 1.02, 1.05) and those with diabetes without complications (OR 1.07, $95 \%$ CI 1.06, 1.08) when compared with COPD without diabetes. The patients' odds of developing respiratory failure were slightly higher in diabetic patients without complications and with complications compared with those without diabetes (1.05 and 1.05, respectively). When compared with patients with COPD and no diabetes, patients with COPD and DM without complications had an odds ratio of 1.086 for acute kidney injury (95\% CI 1.071-1.010) $(p<0.0001)$ COPD and DM with complications had an odds ratio of 1.594 (95\% CI 1.567-1.622) ( $p<0.0001)$. The odds of developing stroke during inpatient admission was not statistically different between COPD without diabetes and COPD and diabetes without complications. There is a statistically significant increased odds of getting stroke among COPD and diabetes with complications compared with COPD alone (OR 1.17, $95 \%$ CI 1.13, 1.22). Surprisingly, both diabetic patients without complications (OR 0.751 $95 \%$ CI $0.727,0.777$ ) and those with complications (OR 0.635, 95\% CI 0.596, and 0.675) had lower odds of mortality than those without diabetes.

Among all the variables, age is a significant factor that can impact mortality. We conducted a multivariate analysis where age was found to have higher odds of mortality independent of DM and other comorbidities with an adjusted odds ratio of 1.033, i.e., for every one-year increase in age, the odds of dying increase by $3.3 \%$ (Table 4 ). 
Table 3. Multivariate logistic regression analysis showing the adjusted odds ratios predicting the specific outcomes for chronic obstructive pulmonary disease hospitalizations.

\begin{tabular}{ccccccccc}
\hline Outcomes & \multicolumn{2}{c}{ DM without Complication vs. No DM } & \multicolumn{3}{c}{ DM with Complication vs. No DM } \\
\hline & Odds Ratio & \multicolumn{2}{c}{$\mathbf{9 5 \%}$ Confidence Interval } & Odds Ratio & \multicolumn{9}{c}{$\mathbf{9 5 \%}$ Confidence Interval } \\
\hline & & Lower & Upper & $\boldsymbol{p}$-Value & & Lower & Upper & $\boldsymbol{p}$-Value \\
\hline LOS $\geq$ 4 days & 1.06 & 1.06 & 1.07 & $<0.0001$ & 1.40 & 1.39 & 1.41 & $<0.0001$ \\
Pneumonia & 1.07 & 1.06 & 1.08 & $<0.0001$ & 1.04 & 1.02 & 1.05 & $<0.0001$ \\
Respiratory failure & 1.05 & 1.04 & 1.07 & $<0.0001$ & 1.05 & 1.04 & 1.07 & $<0.0001$ \\
Acute kidney injury & 1.086 & 1.071 & 1.100 & $<0.0001$ & 1.594 & 1.567 & 1.622 & $<0.0001$ \\
Stroke & 1.018 & 0.994 & 1.042 & 0.143 & 1.179 & 1.136 & 1.225 & $<0.0001$ \\
Inhospital mortality & 0.79 & 0.77 & 0.80 & $<0.0001$ & 0.71 & 0.68 & 0.74 & $<0.0001$ \\
\hline
\end{tabular}

Table 4. Multivariate logistic regression analysis showing the adjusted odds ratios of age predicting the mortality for chronic obstructive pulmonary disease hospitalizations.

\begin{tabular}{ccccc}
\hline Variable & Odds Ratio for Mortality & \multicolumn{9}{c}{$\mathbf{9 5}$ \% Confidence Interval } & $p$-Value \\
\hline Age in years at admission & 1.033 & 1.031 & 1.035 & $<0.0001$ \\
\hline
\end{tabular}

\section{Discussion}

COPD and DM are chronic medical conditions that individually affect the quality of life of patients. If present together, they can further complicate patient management. The impact of these chronic inflammatory conditions has always been an area of interest and public health concern. Observational studies play an essential role in formulating a hypothesis and provide the basis for understanding long-term comorbidities and their association with other medical conditions. Our study provides an insight into understanding the effect of pre-existing DM morbidity, healthcare cost, and mortality of COPD patients. In our study, about $30.45 \%$ of COPD patients had pre-existing DM, of which the study population had greater female representation compared with males. Recent studies have shown that women were more likely than men to have COPD diagnostic delays, inadequate quality of care, a higher frequency of severe exacerbations, a higher number of hospitalizations, and prolonged length of stay for hospitalization [21-23]. Our population also showed women preponderance. Our sample population's mean age was about 68.92 years, almost similar to the prior cohort studies [24].

The longer length of stay, defined as a hospital stay $\geq 4$ days, was higher in diabetic patients with complications than those without diabetes. This was also inferred in the total hospital charges, which were inflated for those patients with diabetes complications. This was seen even in an emergency department (ED) observation unit, as mentioned in a retrospective cohort study conducted in Thailand, where the patients with diabetes had increased odds of prolonged stay at the emergency department $>48 \mathrm{~h}$ or COPD-related ED revisit within $72 \mathrm{~h}$ or readmission within one month [25].

Our study showed that COPD with diabetes has an increased risk of pneumonia and respiratory failure. Our results are similar to the study performed by Ehrlich et al. Their observation between diabetes and COPD showed an increased occurrence of pneumonia in patients with diabetes and decreased pulmonary function related to hyperglycemia [26]. As hyperglycemia is associated with significant lung function decline, we speculate that it could be the reason our COPD hospitalizations with diabetes had higher odds of respiratory failure [27-29].

The limited amount of epidemiological literature on this topic has identified the association of acute kidney disease with COPD. A retrospective cohort study using electronic medical records in Taiwan showed that COPD is associated with a higher risk of acute kidney injury development [30]. Another study showed the possible mechanism of acute kidney injury might probably be due to diuretics and contrast media [31]. Further, pathophysiological changes of acute kidney injury under high-glucose status might be due to 
oxidative stress and increased reactive oxygen species, which cause stronger vessel constriction and insufficient oxygen supply in the kidney via vasoactive substances [32]. Similar to other studies, our study showed that diabetes with complications had much higher odds of acute kidney injury than diabetes without complications on COPD hospitalizations.

In our analysis, we found increased odds of stroke among COPD hospitalizations and diabetes with complications. In general, the association between COPD and stroke is dependent on the other traditional stroke risk factors apart from smoking. COPD and diabetes can cause systemic inflammation, and oxidative stress may play an essential role by promoting cerebral vascular dysfunction and platelet hyperactivity [33,34]. Previous studies have shown that reduced FEV1 is associated with an increased incidence of both ischemic and hemorrhagic stroke, and this association is independent of smoking status [35,36]. Recent meta-analysis also showed that increased $\mathrm{HbA1C}$ is associated with increased prevalence and poor outcomes of stroke among the diabetic patient population [37]. Our study has shown that the combination of COPD and diabetes would increase the odds of stroke, and the odds ratio would be greater with concurrent complications.

Our study found that diabetic patients with and without complications had lower odds of mortality than those without diabetes. This contrasts with a cohort study published by Te-Wei Ho et al. [11]. This study showed that pre-existing DM in COPD patients had a higher hazard ratio (HR) for mortality than those without DM. This could be because of the small sample size and possible mortality, because the majority of the patient population (about $46 \%$ ) were more than 70 years of age. There are potential explanations for our findings. In our data set, COPD hospitalizations with DM were relatively younger and might have a higher body mass index than the COPD patients with no diabetes. Several studies have shown that underweight patients had a higher mortality than COPD patients with normal BMI, whereas overweight and obese individuals were associated with lower mortality [38-42]. In our study, we found that obesity was more common in diabetic patients with complications, and they had lower odds of mortality. It is possible the obesity might have a protective effect against mortality in these patients.

Age alone is a risk factor for mortality in COPD patients, which is evident from our analysis. Kim et al. showed that, after grouping the population by age quartiles, the rate of FEV1 decline was faster among older patients than younger ones [43]. Other studies have also shown that COPD patients had higher odds of inpatient mortality and morbidity, particularly if they were more than 80 years of age [44,45]. So, we included age in the logistic regression as a confounder. After adjusting for all the confounders, including age, mortality was still lower in both groups of diabetes compared with COPD with no diabetes.

\subsection{Strengths}

The large sample size is the study's major strength, representing almost $95 \%$ of U.S. hospitalizations. Our study is the first direct evidence regarding the association between diabetes and health outcomes among COPD hospitalizations in the United States.

\subsection{Study Limitations}

The use of administrative databases has certain limitations. First, because this is a crosssectional observational study, the possibility of selection bias and residual measured and unmeasured confounding cannot be excluded entirely. Second, as NIS is an administrative database, the data's consistency and accuracy depend mainly on the coder's experience and the clinician's documentation. Hence, there may have been a possibility of some variation in the data because of the unrecognized miscoding of diagnostic codes. However, these potential limitations may be compensated for by the large size of the database and the ability to obtain nationwide estimates using the discharge weights provided. Another significant limitation is that NIS is a database of discharges; hence, individual patient analysis, such as the medications, cause of exacerbation (viral vs. bacterial), cause of death, or body mass index, cannot be measured. Besides, we lack information such as pulmonary function tests (PFTs) and the severity of COPD. 


\section{Conclusions}

In conclusion, diabetes is a highly prevalent comorbidity among COPD hospitalizations and is associated with poorer outcomes than COPD hospitalizations without diabetes. If diabetes is associated with complications, there is a strong association with an increased length of stay, increased risk of stroke, and acute kidney injury. Our study highlights the importance of better control of diabetes, particularly in chronic conditions like COPD, to minimize life-threatening complications.

Supplementary Materials: The following are available online at https:/ /www.mdpi.com/2077-038 3/10/2/235/s1, Table S1: ICD codes.

Author Contributions: Conceptualization, K.G., and S.M.; methodology, K.G., and K.E.; writingoriginal draft preparation, K.G., S.M., D.V., S.R., and B.T.; writing-review and editing, V.K.P., A.A., and A.C.; visualization and supervision, K.G. and S.R.; project administration, M.S.R., K.G., and K.P.K.; funding acquisition, K.G. All authors have read and agreed to the published version of the manuscript.

Funding: This research received no external funding.

Institutional Review Board Statement: Ethical review and approval were waived for this study due to the analysis involving only de-identified data.

Informed Consent Statement: Patient consent was waived due to the analysis involving only deidentified data.

Data Availability Statement: The data presented in this study are available on request from the corresponding author.

Acknowledgments: Authors would like to thank Todd Allen Lane, MAT, MLS, Chief of Library services at Yale-New Haven Health Bridgeport Hospital for his help with language editing.

Conflicts of Interest: The authors declare no conflict of interest.

\section{References}

1. Global Strategy for Prevention, Diagnosis and Management of Copd. Global Initiative For Chronic Obstructive Lung Disease. 2020. Available online: www.goldcopd.org (accessed on 20 October 2020).

2. Gunasekaran, K.; Ahmad, M.; Rehman, S.; Thilagar, B.; Gopalratnam, K.; Ramalingam, S.; Paramasivam, V.; Arora, A.; Chandran, A. Impact of a Positive Viral Polymerase Chain Reaction on Outcomes of Chronic Obstructive Pulmonary Disease (COPD) Exacerbations. Int. J. Environ. Res. Public Health 2020, 17, 8072. [CrossRef] [PubMed]

3. Adeloye, D.; Chua, S.; Lee, C.; Basquill, C.; Papana, A.; Theodoratou, E.; Nair, H.; Gasevic, D.; Sridhar, D.; Campbell, H.; et al. Global and regional estimates of COPD prevalence: Systematic review and meta-analysis. J. Glob. Health 2015, 5, 020415. [CrossRef] [PubMed]

4. Murray, C.J.; Barber, R.M.; Foreman, K.J.; Ozgoren, A.A.; Abd-Allah, F.; Abera, S.F.; Aboyans, V.; Abraham, J.P.; Abubakar, I.; Abu-Raddad, L.J.; et al. Global, regional, and national age-sex specific all-cause and cause-specific mortality for 240 causes of death, 1990-2013: A systematic analysis for the Global Burden of Disease Study 2013. Lancet 2015, 385, 117-171. [CrossRef]

5. Lopez, A.D.; Shibuya, K.; Rao, C.; Mathers, C.D.; Hansell, A.L.; Held, L.S.; Schmid, V.; Buist, S. Chronic obstructive pulmonary disease: Current burden and future projections. Eur. Respir. J. 2006, 27, 397-412. [CrossRef]

6. Divo, M.J.; Celli, B.R.; Poblador-Plou, B.; Calderón-Larrañaga, A.; de-Torres, J.P.; Gimeno-Feliu, L.A.; Bertó, J.; Zulueta, J.J.; Casanova, C.; Pinto-Plata, V.M.; et al. Chronic Obstructive Pulmonary Disease (COPD) as a disease of early aging: Evidence from the EpiChron Cohort. PLoS ONE 2018, 13, e0193143. [CrossRef]

7. Mannino, D.M.; Higuchi, K.; Yu, T.C.; Zhou, H.; Li, Y.; Tian, H.; Suh, K. Economic Burden of COPD in the Presence of Comorbidities. Chest 2015, 148, 138-150. [CrossRef]

8. Centers for Disease Control and Prevention. National Diabetes Statistics Report; Centers for Disease Control and Prevention, U.S. Dept of Health and Human Services: Atlanta, GA, USA, 2020.

9. Tsalamandris, S.; Antonopoulos, A.S.; Oikonomou, E.; Papamikroulis, G.A.; Vogiatzi, G.; Papaioannou, S.; Deftereos, S.; Tousoulis, D. The Role of Inflammation in Diabetes: Current Concepts and Future Perspectives. Eur. Cardiol. 2019, 14, 50-59. [CrossRef]

10. Rajasurya, V.; Gunasekaran, K.; Surani, S. Interstitial lung disease and diabetes. World J. Diabetes 2020, 11, 351-357. [CrossRef]

11. Ho, T.W.; Huang, C.T.; Ruan, S.Y.; Tsai, Y.J.; Lai, F.; Yu, C.J. Diabetes mellitus in patients with chronic obstructive pulmonary disease-The impact on mortality. PLoS ONE 2017, 12, e0175794. [CrossRef]

12. Edmonds, P.J.; Gunasekaran, K.; Edmonds, L.C. Neck Grasp Predicts Obstructive Sleep Apnea in Type 2 Diabetes Mellitus. Sleep Disord 2019, 2019, 3184382. [CrossRef] 
13. Mannino, D.M.; Thorn, D.; Swensen, A.; Holguin, F. Prevalence and outcomes of diabetes, hypertension and cardiovascular disease in COPD. Eur. Respir. J. 2008, 32, 962-969. [CrossRef] [PubMed]

14. Parappil, A.; Depczynski, B.; Collett, P.; Marks, G.B. Effect of comorbid diabetes on length of stay and risk of death in patients admitted with acute exacerbations of COPD. Respirology 2010, 15, 918-922. [CrossRef] [PubMed]

15. HCUP Nationwide Inpatient Sample (NIS). In Healthcare Cost and Utilization Project (HCUP). 2002-2014; Agency for Healthcare Research and Quality: Rockville, MD, USA, 2016. Available online: www.hcup-us.ahrq.gov/nisoverview.jsp (accessed on 12 October 2020).

16. Trend Weights for 1993-2011 HCUP NIS Data. In Healthcare Cost and Utilization Project (HCUP). 2002-2011; Agency for Healthcare Research and Quality: Rockville, MD, USA, 2016. Available online: www.hcup-us.ahrq.gov/db/nation/nis/trendwghts.jsp (accessed on 29 May 2020).

17. Houchens, R.R.D.; Elixhauser, A. Final Report on Calculating National Inpatient Sample (NIS) Variances for Data Years 2012 and Later. In HCUP Methods Series Report \# 2015-09 ONLINE; U.S. Agency for Healthcare Research and Quality: Rockville, MD, USA, 2015. Available online: http:/ / www.hcup-us.ahrq.gov/reports/methods/methods.jsp (accessed on 15 September 2020).

18. HCUP Clinical Classifications Software (CCS) for ICD-9-CM. In Healthcare Cost and Utilization Project (HCUP). 2002-2014; Agency for Healthcare Research and Quality: Rockville, MD, USA, 2016. Available online: www.hcup-us.ahrq.gov/toolssoftware/ ccs/ccs.jsp (accessed on 29 May 2020).

19. HCUP Comorbidity Software. In Healthcare Cost and Utilization Project (HCUP). 2002-2014; Agency for Healthcare Research and Quality: Rockville, MD, USA, 2016. Available online: www.hcup-us.ahrq.gov/toolssoftware/comorbidity/comorbidity.jsp (accessed on 29 May 2020).

20. Khera, R.; Angraal, S.; Couch, T.; Welsh, J.W.; Nallamothu, B.K.; Girotra, S.; Chan, P.S.; Krumholz, H.M. Adherence to Methodological Standards in Research Using the National Inpatient Sample. JAMA 2017, 318, 2011-2018. [CrossRef] [PubMed]

21. Martinez, C.H.; Raparla, S.; Plauschinat, C.A.; Giardino, N.D.; Rogers, B.; Beresford, J.; Bentkover, J.D.; Schachtner-Appel, A.; Curtis, J.L.; Martinez, F.J.; et al. Gender differences in symptoms and care delivery for chronic obstructive pulmonary disease. J. Womens Health 2012, 21, 1267-1274. [CrossRef]

22. Kilic, H.; Kokturk, N.; Sari, G.; Cakır, M. Do females behave differently in COPD exacerbation? Int. J. Chron. Obstruct Pulmon Dis. 2015, 10, 823-830. [CrossRef]

23. Montserrat-Capdevila, J.; Godoy, P.; Marsal, J.R.; Barbé, F.; Galván, L. Risk of exacerbation in chronic obstructive pulmonary disease: A primary care retrospective cohort study. BMC Fam. Pract. 2015, 16, 173. [CrossRef]

24. Gayle, A.; Dickinson, S.; Poole, C.; Pang, M.; Fauconnot, O.; Quint, J.K. Incidence of type II diabetes in chronic obstructive pulmonary disease: A nested case-control study. NPJ Prim. Care Respir. Med. 2019, 29, 28. [CrossRef]

25. Pethyabarn, W.; Chewae, S.; Dadeh, A.A. Factors Associated with Treatment Failure in Patients with Acute Exacerbation of COPD Admitted to the Emergency Department Observation Unit. Emerg. Med. Int. 2020, 2020, 8261375. [CrossRef]

26. Ehrlich, S.F.; Quesenberry, C.P.; Van Den Eeden, S.K.; Shan, J.; Ferrara, A. Patients diagnosed with diabetes are at increased risk for asthma, chronic obstructive pulmonary disease, pulmonary fibrosis, and pneumonia but not lung cancer. Diabetes Care 2010, 33, 55-60. [CrossRef]

27. Torres, A.; Blasi, F.; Dartois, N.; Akova, M. Which individuals are at increased risk of pneumococcal disease and why? Impact of COPD, asthma, smoking, diabetes, and/or chronic heart disease on community-acquired pneumonia and invasive pneumococcal disease. Thorax 2015, 70, 984-989. [CrossRef]

28. Chan, S.M.H.; Selemidis, S.; Bozinovski, S.; Vlahos, R. Pathobiological mechanisms underlying metabolic syndrome (MetS) in chronic obstructive pulmonary disease (COPD): Clinical significance and therapeutic strategies. Pharmacol. Ther. 2019, 198, 160-188. [CrossRef] [PubMed]

29. Gläser, S.; Krüger, S.; Merkel, M.; Bramlage, P.; Herth, F.J. Chronic obstructive pulmonary disease and diabetes mellitus: A systematic review of the literature. Respiration 2015, 89, 253-264. [CrossRef] [PubMed]

30. Hsu, C.N.; Lee, C.T.; Su, C.H.; Wang, Y.C.; Chen, H.L.; Chuang, J.H.; Tain, Y.L. Incidence, Outcomes, and Risk Factors of Community-Acquired and Hospital-Acquired Acute Kidney Injury: A Retrospective Cohort Study. Medicine 2016, 95, e3674. [CrossRef] [PubMed]

31. Wang, X.; Xie, Z.; Xiong, S.; Xiong, W.; Zhong, T.; Su, Y. Acute kidney injury in hospitalized patients with nonexacerbated chronic obstructive pulmonary disease. BMC Pulm. Med. 2020, 20, 108. [CrossRef] [PubMed]

32. Li, Y.; Ren, K. The Mechanism of Contrast-Induced Acute Kidney Injury and Its Association with Diabetes Mellitus. Contrast Media Mol. Imaging 2020, 2020, 3295176. [CrossRef] [PubMed]

33. Austin, V.; Crack, P.J.; Bozinovski, S.; Miller, A.A.; Vlahos, R. COPD and stroke: Are systemic inflammation and oxidative stress the missing links? Clin. Sci. 2016, 130, 1039-1050. [CrossRef] [PubMed]

34. Hill, M.D. Stroke and diabetes mellitus. Handb. Clin. Neurol. 2014, 126, 167-174. [CrossRef] [PubMed]

35. Gulsvik, A.K.; Gulsvik, A.; Skovlund, E.; Thelle, D.S.; Mowé, M.; Humerfelt, S.; Wyller, T.B. The association between lung function and fatal stroke in a community followed for 4 decades. J. Epidemiol. Community Health 2012, 66, 1030-1036. [CrossRef]

36. Truelsen, T.; Prescott, E.; Lange, P.; Schnohr, P.; Boysen, G. Lung function and risk of fatal and non-fatal stroke. The Copenhagen City Heart Study. Int. J. Epidemiol. 2001, 30, 145-151. [CrossRef]

37. Lau, L.H.; Lew, J.; Borschmann, K.; Thijs, V.; Ekinci, E.I. Prevalence of diabetes and its effects on stroke outcomes: A meta-analysis and literature review. J. Diabetes Investig. 2019, 10, 780-792. [CrossRef] 
38. Cao, C.; Wang, R.; Wang, J.; Bunjhoo, H.; Xu, Y.; Xiong, W. Body mass index and mortality in chronic obstructive pulmonary disease: A meta-analysis. PLoS ONE 2012, 7, e43892. [CrossRef] [PubMed]

39. Guo, Y.; Zhang, T.; Wang, Z.; Yu, F.; Xu, Q.; Guo, W.; Wu, C.; He, J. Body mass index and mortality in chronic obstructive pulmonary disease: A dose-response meta-analysis. Medicine 2016, 95, e4225. [CrossRef] [PubMed]

40. Divo, M.J.; Cabrera, C.; Casanova, C.; Marin, J.M.; Pinto-Plata, V.M.; de-Torres, J.P.; Zulueta, J.; Zagaceta, J.; Sanchez-Salcedo, P.; Berto, J.; et al. Comorbidity Distribution, Clinical Expression and Survival in COPD Patients with Different Body Mass Index. Chronic Obstr. Pulm Dis 2014, 1, 229-238. [CrossRef] [PubMed]

41. Wu, T.D.; Ejike, C.O.; Wise, R.A.; McCormack, M.C.; Brigham, E.P. Investigation of the Obesity Paradox in Chronic Obstructive Pulmonary Disease, According to Smoking Status, in the United States. Am. J. Epidemiol. 2019, 188, 1977-1983. [CrossRef] [PubMed]

42. Altinoz, H.; Adiguzel, N.; Salturk, C.; Gungor, G.; Mocin, O.; Berk Takir, H.; Kargin, F.; Balci, M.; Dikensoy, O.; Karakurt, Z Obesity might be a good prognosis factor for COPD patients using domiciliary noninvasive mechanical ventilation. Int. J. Chron. Obstruct Pulmon Dis. 2016, 11, 1895-1901. [CrossRef]

43. Kim, S.J.; Lee, J.; Park, Y.S.; Lee, C.H.; Yoon, H.I.; Lee, S.M.; Yim, J.J.; Kim, Y.W.; Han, S.K.; Yoo, C.G. Age-related annual decline of lung function in patients with COPD. Int. J. Chron. Obstruct Pulmon Dis. 2016, 11, 51-60. [CrossRef]

44. Morasert, T.; Jantarapootirat, M.; Phinyo, P.; Patumanond, J. Prognostic indicators for in-hospital mortality in COPD with acute exacerbation in Thailand: A retrospective cohort study. BMJ Open Respir. Res. 2020, 7. [CrossRef]

45. Stone, R.A.; Lowe, D.; Potter, J.M.; Buckingham, R.J.; Roberts, C.M.; Pursey, N.J. Managing patients with COPD exacerbation: Does age matter? Age Ageing 2012, 41, 461-468. [CrossRef] 